\title{
Highly Antibacterial Efficacy of a Cotton Fabric Treated with Piperazinyl Schiff Base
}

\author{
Wen Wen ${ }^{1}$, Zaixing Zhang ${ }^{2 *}$, Lingxiao Jing ${ }^{1}$, and Tonghua Zhang ${ }^{1 *}$ \\ ${ }^{1}$ College of Sericulture, Textile and Biomass Sciences, Southwest University, Chongqing Engineering Research \\ Center of Biomaterial Fiber and Modem Textile, Chongqing 400715, China \\ ${ }^{2}$ Chemistry and Material Engineering School of Huaihua University, Hunan Engineering Laboratory for \\ Preparation Technology of Polyvinyl Alcohol Fiber, Huaihua 418008, China
}

(Received February 24, 2021; Revised April 24, 2021; Accepted April 29, 2021)

\begin{abstract}
Due to the structure of hierarchical aligned cellulose fibrils, cotton fabric used in clothing possesses excellent moisture and thermal managements. Such structure yet may retain metabolic excrements and sebum secretions discharged from the human skin, which reproduce microorganisms harmful for human health. However, incorporating the antimicrobial coating into the cotton fabric can sufficiently resist the microorganism growth. In this work, a water-soluble antibacterial coating named N-(4-(allyloxy) benzylidene)-2-(piperazin-1-yl) ethanamine (NABPE) was synthesized to produce a rechargeable and fast sterilization cotton fiber fabric (M-cotton/NABPE). M-cotton/NABPE exhibited a high effective antibacterial activity, and the inhibition ratios against Escherichia coli $(E$. coli) and Staphylococcus aureus $(S$. aureus) were $94 \%$ and $93 \%$, respectively. Chlorination was performed with sodium hypochlorite solution to form N-Cl bond on the Mcotton/NABPE fabrics, resulting in a high biocidal efficacy of up to $100 \%$ via contact killing for a duration of 5 min. After 25 washing cycles, the antibacterial fabric still maintained an antibacterial rate of $91.95 \%$ and $92.15 \%$ against E. coli and $S$. aureus, respectively. Furthermore, the fabrics showed integrated properties of excellent UV stability, long-term stability, robust rechargeable biocidal activity (chlorine recharging $>5000 \mathrm{ppm}$ ) and washing durability. This research provides fundamental insights into the synthesis of the NABPE and prolonged biocidal efficacy of the M-cotton/NABPE, and thereby pave a pathway to incorporate an economic and environmental-friendly antibacterial coating suitable for finishing cotton fabric.
\end{abstract}

Keywords: Cotton fabric, Piperazinyl schiff base, Antibacterial performance, Rechargeable, Stability

\section{Introduction}

Cotton fiber fabric performs very well in sweat/moisture absorption and release, and also shows a good absorption of metabolic products and sebum secretions released from the skin [1]. Those matters may provide nutrient sources for fostering microorganisms, such as bacteria, fungi and even virus [2,3]. Under certain scenarios, the microorganisms can proliferate rapidly to form biofilms on fabric surface, resulting in cross contamination and unpleasant odor. Those may cause potential health risks $[2,4,5]$. Therefore, the development of an efficient and durable agent for the antibacterial finish of cotton fabric is urgently needed.

$\mathrm{N}$-halamines, a group of compounds containing one or more nitrogen-halogen covalent bonds, have been increasingly used in antibacterial applications, because of their excellent antibacterial activity, biosafety, and environment-friendliness [6-10]. They can be produced by bonding nitrogen on the inorganic or organic compounds and oxidative halogens [11]. Due to the strong oxidative state of halogen atoms in the bonds, N-halamines show a powerful antibacterial activity against pathogenic bacteria [12,13]. In the past, various N-halamine precursors with different reactive groups, such as siloxane bonds [14-21] and epoxy groups

*Corresponding author: xgkzhzx@126.com

*Corresponding author: 398112773@qq.com
[22-24], have been developed and applied to fabricate durable and desirable antibacterial textiles. Meanwhile, harmful organic solvents were used in the finishing process. Given the eco-friendly preparation process and practical application, reactive $N$-halamine precursors with good water solubility should be considered.

Recently, harmless $N$-halamine precursors such as cationic/anionic $N$-halamine polymers [25], $N$-halaminebased cyclic polysiloxane compound [26], and quaternarized $N$-halamine precursors [27] were designed to enhance antimicrobial efficacy. Also, antibacterial cotton fabrics can be prepared through thiol-ene click reaction [28]. In our previous work, an $N$-halamine precursor (Hein-Schiff base AOBYID) with a reactive $-\mathrm{C}=\mathrm{C}$ - group was synthesized to produce cotton fabrics with highly effective bactericidal properties [29]. Improving the water solubility of the $\mathrm{N}$ halamine precursor might be an effective method to further expand its antibacterial application.

In this study, a water-soluble $\mathrm{N}$-halamine precursor $\mathrm{N}-(4-$ (allyloxy)benzylidene)-2-(piperazin-1-yl)ethanamine (NABPE) was synthesized by introducing 1-(2-aminoethyl)piperazine (AEP) for cotton fabric antibacterial finishing. Meanwhile, the antibacterial activities of AOBYID and NABPE were compared. The antibacterial properties, stability and rechargeability of NABPE treated cotton fabrics were investigated. The cotton fabrics' properties such as tensile strength, whiteness, and softness were also evaluated after 
treatment with NABPE.

\section{Experimental}

\section{Materials}

Bleached cotton fabric $\left(142 \mathrm{~g} / \mathrm{m}^{2}\right)$ was purchased from Chongqing Beibei wholesale market. N-Aminoethylpiperazine (AEP), P-hydroxybenzaldehyde, 3-bromopropene, petroleum ether, sodium bicarbonate, 1-aminohein hydrochloride and $\mathrm{Na}_{2} \mathrm{~S}_{2} \mathrm{O}_{3}$ solution $(0.1000 \mathrm{~mol} / \mathrm{L})$ were obtained from the Shanghai Aladdin Biochemical Technology Co., Ltd. Anhydrous potassium carbonate was from Chongqing Chuandong Chemical (Group) Co., Ltd. 3-Mercaptopropyltriethoxysilane (MPTES) and sodium hypochlorite solution (6\%-14 \% active chlorine basis) were supplied by Shanghai Macklin Biochemical Technology Co., Ltd. Peptone and 2,2-Bis (hydroxymethyl) propionic acid (DMPA) were purchased from Shanghai Yuanye Biological Technology Co., Ltd. Staphylococcus aureus (S. aureus, ATCC 6538) and Escherichia coli (E. coli, ATCC 25922) were purchased from Nantong KingHunt Biology Technological Development Co., Ltd. Hein was obtained by 1-aminohein hydrochloride [11]. All chemicals were of analytical grade and used without further purification.

\section{Synthesis of N-(4-(allyloxy) benzylidene)-2-(piperazin-1-yl) ethanamine (NABPE)}

The synthesis route of N-(4-(allyloxy) benzylidene)-2(piperazin-1-yl) ethanamine (NABPE) was presented in Scheme 1. First, anhydrous potassium carbonate $(20.73 \mathrm{~g}$, $0.15 \mathrm{~mol})$, P-hydroxybenzaldehyde (1, $12.212 \mathrm{~g}, 0.1 \mathrm{~mol})$, and $100 \mathrm{ml}$ of ethanol were mixed in a round bottom flask $(250 \mathrm{ml})$. Then, 3-bromopropene was added $(2,12.098 \mathrm{~g}$, $0.1 \mathrm{~mol})$. The solution was placed in an oil bath with a magnetic stirrer and stirred under reflux at $70{ }^{\circ} \mathrm{C}$ for $18 \mathrm{~h}$. The salt was filtered under reduced pressure, the solvent ethanol was evaporated, and the residue was purified with petroleum ether, resulting in a pale reddish-brown liquid 3 (4-(allyloxy)benzaldehyde). Secondly, liquid 3 (1.77 g, $0.01 \mathrm{~mol}$ ) and $60 \mathrm{ml}$ ethanol were mixed in a round bottom flask $(250 \mathrm{~m} l)$. N-aminoethylpiperazine $(4,1.938 \mathrm{~g}, 0.015$ mol) was added dropwise. The solution was stirred under reflux at $70{ }^{\circ} \mathrm{C}$ for $18 \mathrm{~h}$. After the reaction was completed, the product NABPE 5 with a yellow viscous liquid was obtained through filtration and distillation.

\section{Preparation of Antibacterial Cotton Fabric}

Cotton fabric was first cleaned with deionized water at $80^{\circ} \mathrm{C}$ for $20 \mathrm{~min}$ to remove the surface impurities and then

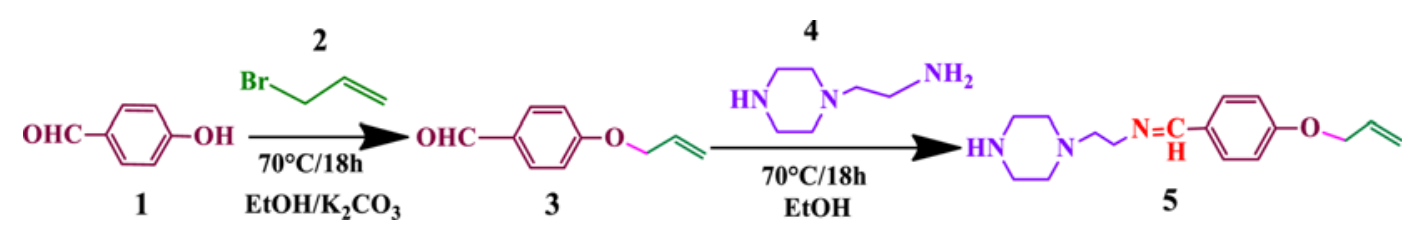

Scheme 1. Synthesis route of piperazinyl Schiff base, NABPE.

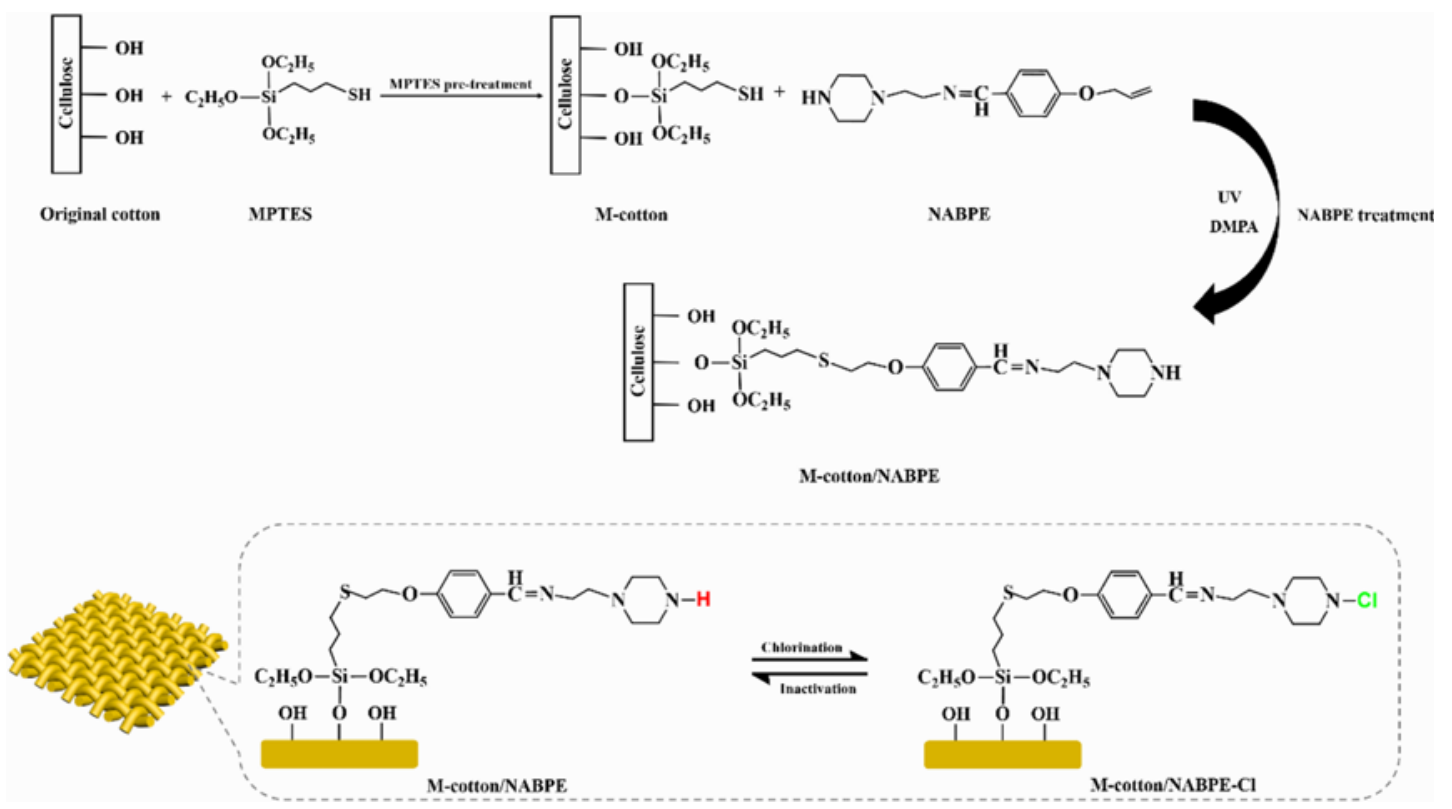

Scheme 2. Preparation mechanism of antibacterial cotton fabric. 
dried at $60{ }^{\circ} \mathrm{C}$. Anhydrous ethanol and distilled water were mixed at 4:1 ratio, and MPTES (5 wt.\%) was added. The $\mathrm{pH}$ of the mixture was adjusted to 3.5 with acetic acid. Afterward, the mixed solution was continuously stirred at $25^{\circ} \mathrm{C}$ for $30 \mathrm{~min}$. The cotton fabric was immersed into the above solution for $3 \mathrm{~min}$ and solidified at $120^{\circ} \mathrm{C}$ for $1 \mathrm{~min}$. The MPTES pre-treated cotton fabric was obtained and marked as M-cotton. The photoinitiator DMPA (0.1 wt.\%) was added into NABPE finishing solution $(40 \mathrm{mg} / \mathrm{m} l)$ to make the mixed solution. Then, the M-cotton was immersed in the mixed solution and exposed to ultraviolet rays for $30 \mathrm{~min}$. Afterward, the M-cotton was fully washed and dried at $60^{\circ} \mathrm{C}$. Cotton fabrics treated with NABPE were obtained and marked as M-cotton/NABPE.

M-cotton/NABPE was treated with $10 \%$ sodium hypochlorite solution $(\mathrm{pH}=7)$ for $20 \mathrm{~min}$, washed in deionized water, and dried at $45^{\circ} \mathrm{C}$ for $1 \mathrm{~h}$. $N$-halamine functionalized cotton fabrics were obtained and marked as M-cotton/ NABPE-Cl. Scheme 2 illustrates the reaction between the NABPE and the cellulose of the cotton fiber.

\section{Determination of Oxidative Chlorine Content}

Oxidative chlorine content of the M-cotton/NABPE-Cl was determined by using the modified iodometric/thiosulfate titration method [14]. The percentage of oxidative chlorine $\left(\mathrm{Cl}^{+} \%\right)$ was calculated on the basis of the following equation:

$$
\mathrm{Cl}^{+} \%=\frac{35.45}{2} \times \frac{N \times V_{c} \times 10^{-3}}{W} \times 100
$$

where $N$ and $V_{c}$ are the normality (equiv./L) and volume $(\mathrm{m} l)$ of titrant sodium thiosulfate, respectively. $\mathrm{W}$ is the weight of the samples (g).

\section{Characterization}

The Fourier transform infrared (FT-IR) spectroscopy of NABPE, original cotton, and NABPE-treated cotton fabrics before and after chlorination, were characterized by ALPHA infrared spectrometer (Bruker, GER). The ${ }^{1} \mathrm{H}-\mathrm{NMR}$ spectra of NABPE was recorded on a WNMR-I-400 MHz spectrometer. Dimethyl sulfoxide (DMSO) and tetramethylsilane (TMS) were used as solvent and internal standard, respectively. The surface functional groups of M-cotton were investigated by Raman analysis (DXR2, ThermoFisher Scientific, USA) in the range of $3000-2000 \mathrm{~cm}^{-1}$. Surface morphologies of the fabrics were observed by scanning electron microscopy (Hitachi S-4800, Netherlands). Surface elemental analysis of the fabrics was conducted by Thermo Scientific K-Alpha Xray photoelectron spectrometer (XPS).

\section{Stability and Rechargeability}

The stability performance of the M-cotton/NABPE-Cl fabric was evaluated by UV irradiation, long-term storage at room temperature, and washing cycles. For the UV irradiation test, nine sets of fabric samples were irradiated under UV light (Type A, $315-400 \mathrm{~nm}, 0.68 \mathrm{~W} / \mathrm{m}^{2}$, RT $60{ }^{\circ} \mathrm{C}$ ) for $1,2,3,4,6,8,10,12$ and $24 \mathrm{~h}$, respectively. For storage stability test, six sets of fabric samples were stored at room temperature and under laboratory light for 1, 5, 9, 13, 17 and 21 days, respectively. For washing stability test, four sets of fabric samples were used for washing cycles of 5, 10, 20 and 25 times, respectively. For the above three tests, each set of samples was divided into two parts. One part was titrated directly to calculate the content of the remained oxidative chlorines. The other part was first recharged with sodium hypochlorite solution and then titrated to characterize the rechargeability of lost oxidative chlorines.

The rechargeability test of M-cotton/NABPE-Cl fabric was carried out by chlorination-quenching cycles (repeated 10 times). The fabric was first chlorinated for $20 \mathrm{~min}$ and then fully quenched with an excess amount of thiosulfate solution $(0.02 \mathrm{~N})$ for $10 \mathrm{~min}$. The fabric was further chlorinated under the same chlorination conditions and then titrated.

Minimum Inhibitory Concentration (MIC) and Minimum Bactericidal Concentration (MBC) Determination of NABPE

MIC is the minimum concentration at which an antibacterial agent can inhibit bacterial growth in the medium. $\mathrm{MBC}$ is the lowest concentration that the antibacterial agent can kill above $99 \%$ bacteria in the culture medium [30]. MIC and MBC are the indexes of antibacterial activity of antibacterial agents, defining the ability of killing pathogenic microorganisms.

The MIC of NABPE against $E$. coli and $S$. aureus was determined through a serial dilution method. NABPE's diluents were prepared in a series test tubes at a concentration range of $0.25-512 \mathrm{mg} / \mathrm{ml}$. Then, sterile test tubes 1-12 were filled with $2 \mathrm{~m} l$ of the above NABPE's diluents and $4 \mathrm{~m} l$ Luria-Bertani (LB) liquid medium. At last, diluents at 12 concentrations $(128.00,64.00,32.00,16.00$, $8.00,4.00,2.00,1.00,0.50,0.25,0.125$, and $0.0625 \mathrm{mg} / \mathrm{m} l$ ) were obtained by adding $2 \mathrm{ml} 1 \times 10^{6}$ of the bacterial suspension $\left(\mathrm{CFU} \mathrm{m} l^{-1}\right)$ into the tubes. The tubes were then placed in a vibrating incubator at $37^{\circ} \mathrm{C}$ and $150 \mathrm{rpm}$ for $18 \mathrm{~h}$. The minimum concentration without visible turbidity was considered as the MIC of NABPE. To obtain the NABPE's MBC, agar plates were first prepared by pouring the LB onto sterilized Petri dishes for solidification. Then, $100 \mu l$ of bacterial culture were taken out from tubes 1-12 in the MIC test and inoculated uniformly onto the surface of agar plate. The plates were incubated at $37^{\circ} \mathrm{C}$ for $24 \mathrm{~h}$.

\section{Antibacterial Performance Test}

According to the modified antibacterial test method in our previous work [29], the antibacterial agent's type was characterized by the Zone of Inhibition (ZOI). The biocidal efficacies of antibacterial fabrics were evaluated by methods of plate counting and optical density at $600 \mathrm{~nm}$ (OD600). 


\section{Results and Discussion}

\section{Characterization of NABPE}

Figure 1(a) showed the FT-IR spectrum of NABPE. The peak at around $3362 \mathrm{~cm}^{-1}$ was attributed to the stretching vibration of $\mathrm{N}-\mathrm{H}$ group. The absorption peaks at 2945 and $2525 \mathrm{~cm}^{-1}$ were ascribed to the asymmetric and symmetric stretching vibration of $-\mathrm{CH}_{2}$ - bonds, respectively. The signal peak at around $2266 \mathrm{~cm}^{-1}$ possibly represented the contact with the stretching vibration of $=\mathrm{C}-\mathrm{H}$ bonds. The peak at $1643 \mathrm{~cm}^{-1}$ was assigned to the stretching vibration of the $\mathrm{C}=\mathrm{C}$ bonds. The peak at $1604 \mathrm{~cm}^{-1}$ was attributed to the stretching vibration of $\mathrm{C}=\mathrm{N}$, whereas those at 1578,1510 , and $1461 \mathrm{~cm}^{-1}$ were assigned to the skeleton vibrations of the benzene ring. The absorption peak at $1322 \mathrm{~cm}^{-1}$ was caused by the deformation vibration of $\mathrm{N}-\mathrm{H}$ bonds, whereas the peak at $1136 \mathrm{~cm}^{-1}$ was caused by the stretching vibration of C-O. The peak near $1000 \mathrm{~cm}^{-1}$ is ascribed to the bending vibration of $\mathrm{C}-\mathrm{H}$ in the olefin. The peaks at 939,840 , and $761 \mathrm{~cm}^{-1}$ were ascribed to the bending vibration of the C-H bond on the benzene ring. Based on the above peaks, we deduced the existence of NABPE.

${ }^{1} \mathrm{H}$ NMR spectrum was used to further determine the chemical structure of NABPE (Figure 1(b)). The absorption peak near $3.33 \mathrm{ppm}$ belonged to $\mathrm{H}_{2} \mathrm{O}$. The characteristic peaks of ${ }^{1} \mathrm{H}$ NMR (DMSO) $\delta_{\mathrm{H}}: 8.23(\mathrm{~s}, 1 \mathrm{H}, \mathrm{N}=\mathrm{CH})(\mathrm{a} 1)$, 7.64 (d, J=8.6 Hz, 2H, Ar-H) (a2), 6.99 (d, J=8.68 Hz, 2H, Ar-H) (a3), 6.06 (m, J=27.84 Hz, 1H, double bond CH) (a4), 5.42 (dd, J=17.3 Hz, 1H, double bond $\mathrm{CH}_{2}$ ) (a5), 5.28 (d, $\mathrm{J}=11.8 \mathrm{~Hz}, 1 \mathrm{H}$, double bond $\left.\mathrm{CH}_{2}\right)(\mathrm{a} 6), 4.60(\mathrm{~d}, \mathrm{~J}=5.12 \mathrm{~Hz}$, $\left.2 \mathrm{H}, \mathrm{CH}_{2}\right)(\mathrm{a} 7), 3.62\left(\mathrm{t}, 2 \mathrm{H}, \mathrm{CH}_{2}\right)(\mathrm{a} 8), 2.35\left(\mathrm{~s}, 4 \mathrm{H}, \mathrm{CH}_{2}\right)(\mathrm{a} 9-$ 11), and 2.25 (t, $\left.7 \mathrm{H}, \mathrm{J}=13.08 \mathrm{~Hz}, \mathrm{CH}_{2}, \mathrm{NH}\right)(\mathrm{a} 9-11)$. The AABB shift peak in the range of 6.5-8 ppm indicates the presence of benzene ring and para substitution; the characteristic peak near $5 \mathrm{ppm}$ belongs to $=\mathrm{CH}_{2}$; and the characteristic peak at $8.23 \mathrm{ppm}$ belongs to $\mathrm{N}=\mathrm{C}-\mathrm{H}$. Hence, it can be concluded that NABPE was successfully synthesized.

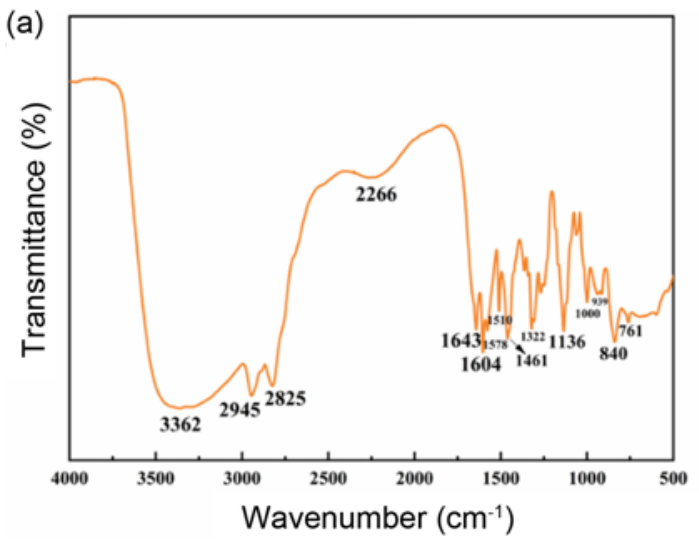

\section{Antibacterial Activity of NABPE}

Figure 2 shows the testing results of the antibacterial activity of agents against $E$. coli and $S$. aureus. Table 1 shows the corresponding antibacterial rates of AOBYID and NABPE.

Figure 2(a) shows that AEP (3) had an aseptic circle, whereas Hein (2) had none. AEP's aseptic circle for $S$. aureus was larger than for E. coli, indicating that AEP had a higher antibacterial activity and a better killing effect against $S$. aureus. Moreover, NABPE has the antibacterial rate of over $99 \%$ against both E. coli and $S$. aureus, while AOBYID has lower antibacterial (in Figure 2(b) and Table 1). The lowest MIC of NABPE ( 4 and $2 \mathrm{mg} / \mathrm{ml}$ for E. coli and $S$. aureus, respectively) and $\mathrm{MBC}(8$ and $2 \mathrm{mg} / \mathrm{m} l$ for $E$. coli and $S$. aureus, respectively) were determined (Figure 2(c) and Figure 2(d)). As a result, the NABPE exhibited better antibacterial activity against both $E$. coli and $S$. aureus than the AOBYID of our previous work [29].

\section{Fabric Characterizations \\ Structural Analysis}

FT-IR, Raman, and XPS were used to determine the difference in cotton fabric's chemical composition before and after NABPE treatment (Figure 3).

As shown in Figure 3(a), in M-cotton/NABPE, three new characteristic peaks appeared at 825,1029 , and $1341 \mathrm{~cm}^{-1}$, which belong to the out-of-plane bending vibration of the benzene ring, the stretching vibration of the amine C-N bond, and the stretching vibration of the $\mathrm{C}-\mathrm{N}$ bond, respectively. Besides, the peak at $1507 \mathrm{~cm}^{-1}$ was attributed to the deformation vibration of the secondary amine groups (-NH-) of NABPE. After chlorination, $\mathrm{N}-\mathrm{H}$ was changed to $\mathrm{N}-\mathrm{Cl}$, as evidenced by the disappearance of the peak at $1507 \mathrm{~cm}^{-1}$ [31].

M-cotton was further analyzed by Raman spectroscopy. Compared with original cotton, M-cotton exhibited a new peak at approximately $2569 \mathrm{~cm}^{-1}$ (Figure 3(b)), which was

(b)

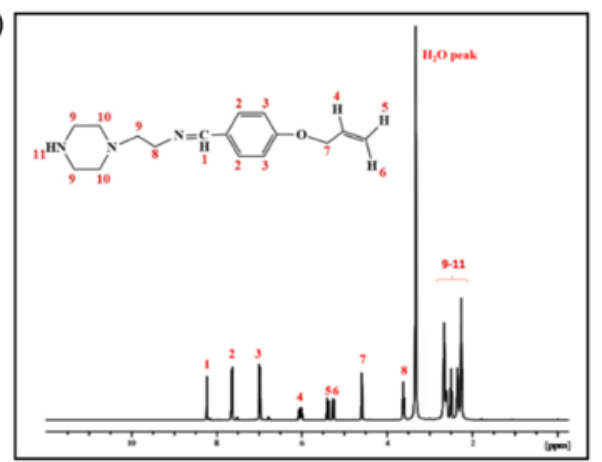

Figure 1. (a) Exhibited the FTIR spectra of NABPE and (b) displayed the ${ }^{1} \mathrm{H}$ NMR of NABPE. 

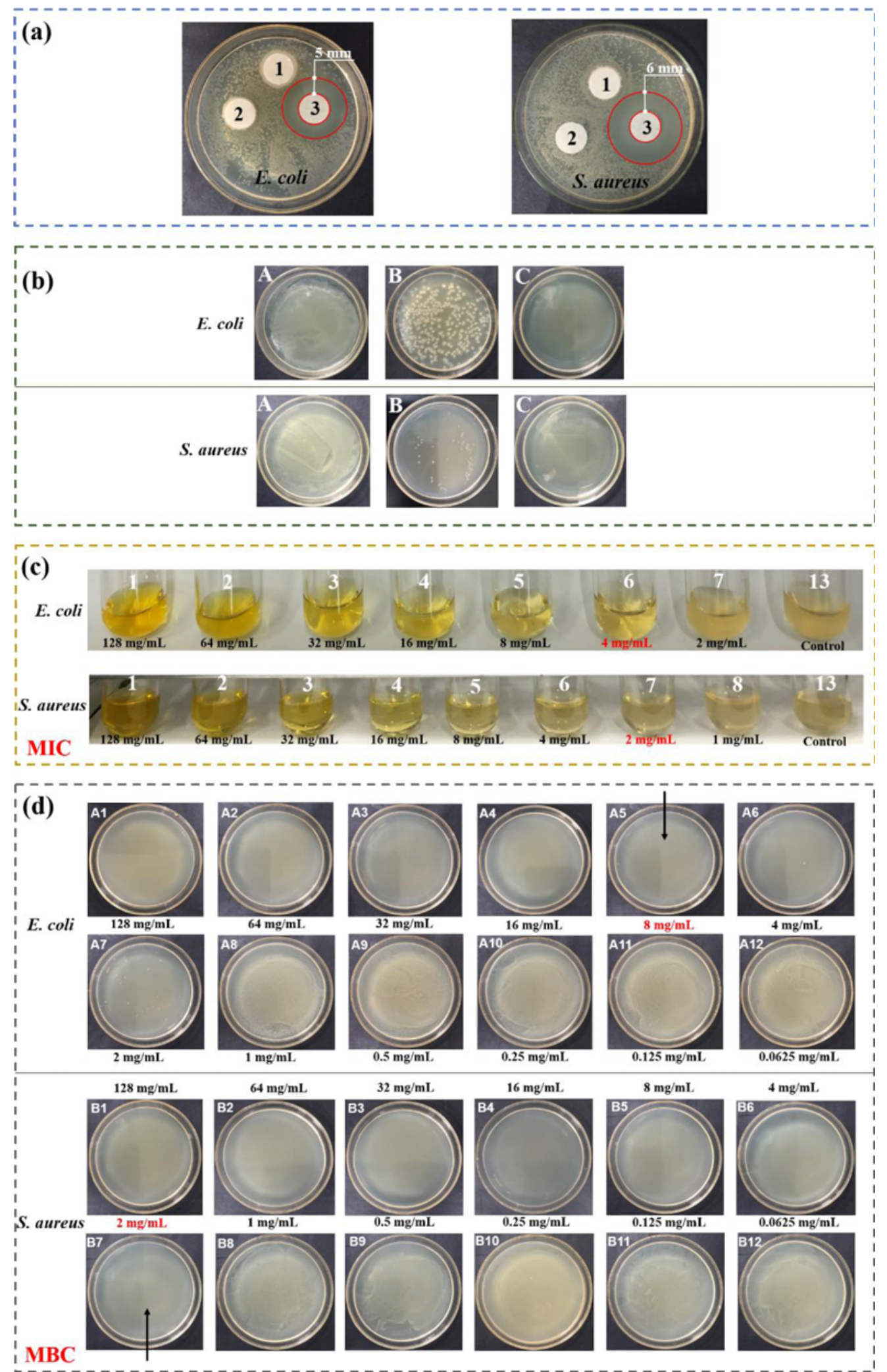

Figure 2. (a) Shows the testing results of the antibacterial activity against E. coli and S. aureus on Hein (2) and AEP (3), and 1 is the blank control sample; (b) is the testing results of the antibacterial activity against E. coli and $S$. aureus about AOBYID (B) and NABPE (C), A is blank control. (c) and (d) respectively show the MIC and MBC of NABPE against E. coli (A1-12) and S. aureus (B1-12), respectively. 
Table 1. Antibacterial activity test results

\begin{tabular}{cccc}
\hline \multirow{2}{*}{ Sample } & ${\text { E. } \text { coli }^{\mathrm{a}}}$ & & S. aureus $^{\mathrm{b}}$ \\
\cline { 2 - 3 } Blank & Bacterial reduction (\%) & & Bacterial reduction $(\%)$ \\
AOBYID & - & - \\
NABPE & 74.73 & 85.95 \\
\hline
\end{tabular}

anoculum concentration was $7.32 \times 10^{8} \mathrm{CFU} /$ sample and ${ }^{\mathrm{b}}$ inoculum concentration was $7.19 \times 10^{8} \mathrm{CFU} /$ sample.

due to the vibration of the -SH $[32,33]$.

XPS measurements were further performed to confirm the existence of NABPE on treated fabric, and the results are shown in Figure 3(c-g).

Compared with the original cotton, M-cotton exhibited new elements $\mathrm{S}$ and $\mathrm{Si}$, while M-cotton/NABPE shows the element $\mathrm{N}$ (Figure 3(c)). A new characteristic peak at $286.35 \mathrm{eV}(\mathrm{C} 1 \mathrm{~s})$ of M-cotton and M-cotton/NABPE was detected (Figure 3(e) and 3(f)) compared with what is shown in Figure 3(d), indicating the presence of MPTES on the cotton sample. In addition, the high-resolution N1s spectra of M-cotton/NABPE (Figure 3(g)) could be deconvoluted into three individual component groups $(\mathrm{C}-\mathrm{N}, \mathrm{C}=\mathrm{N}$, and $\mathrm{N}-\mathrm{H})$ at $399.34,400.62$ and $402.16 \mathrm{eV}$, respectively. The above results indicate that NABPE was covalently linked on the fiber surface.

\section{Surface Morphology}

The surface structures of cotton fiber before and after treatment were further studied by scanning electron microscopy (SEM), and the results are shown in Figure 4. In Figure 4(a), (b), the original cotton exhibits a rough surface structure with clear ravines. The similar surface structures but smoother characteristics are exhibited by M-cotton/ NABPE, which might be due to a thin NABPE film on the cotton fiber (Figure 4(c), (d)). Thus, NABPE treatment has a minimal effect on the surface morphology of the fabric.

\section{Antibacterial Properties of Fabrics}

Figure 5 showed the testing results of the fabric's antibacterial properties against $E$. coli and $S$. aureus. The method OD600 was introduced to quantitatively determine the inhibition effects of M-cotton/NABPE and M-cotton/ NABPE-Cl against E. coli and $S$. aureus. As shown in Figure 5(a), the solutions in tube 1 (blank) and tube 2 (control cotton fabric) were turbid, whereas those in tubes 3 and 4 (M-cotton/NABPE and M-cotton/NABPE-Cl) were clear. According to the histogram, the antibacterial rates of non- $N$-halamine functionalized cotton fabric (M-cotton/ NABPE) against $E$. coli and $S$. aureus were up to $94 \%$ and $93 \%$, respectively. The $N$-halamine functionalized cotton fabrics treated with chlorination (M-cotton/NABPE-Cl) had

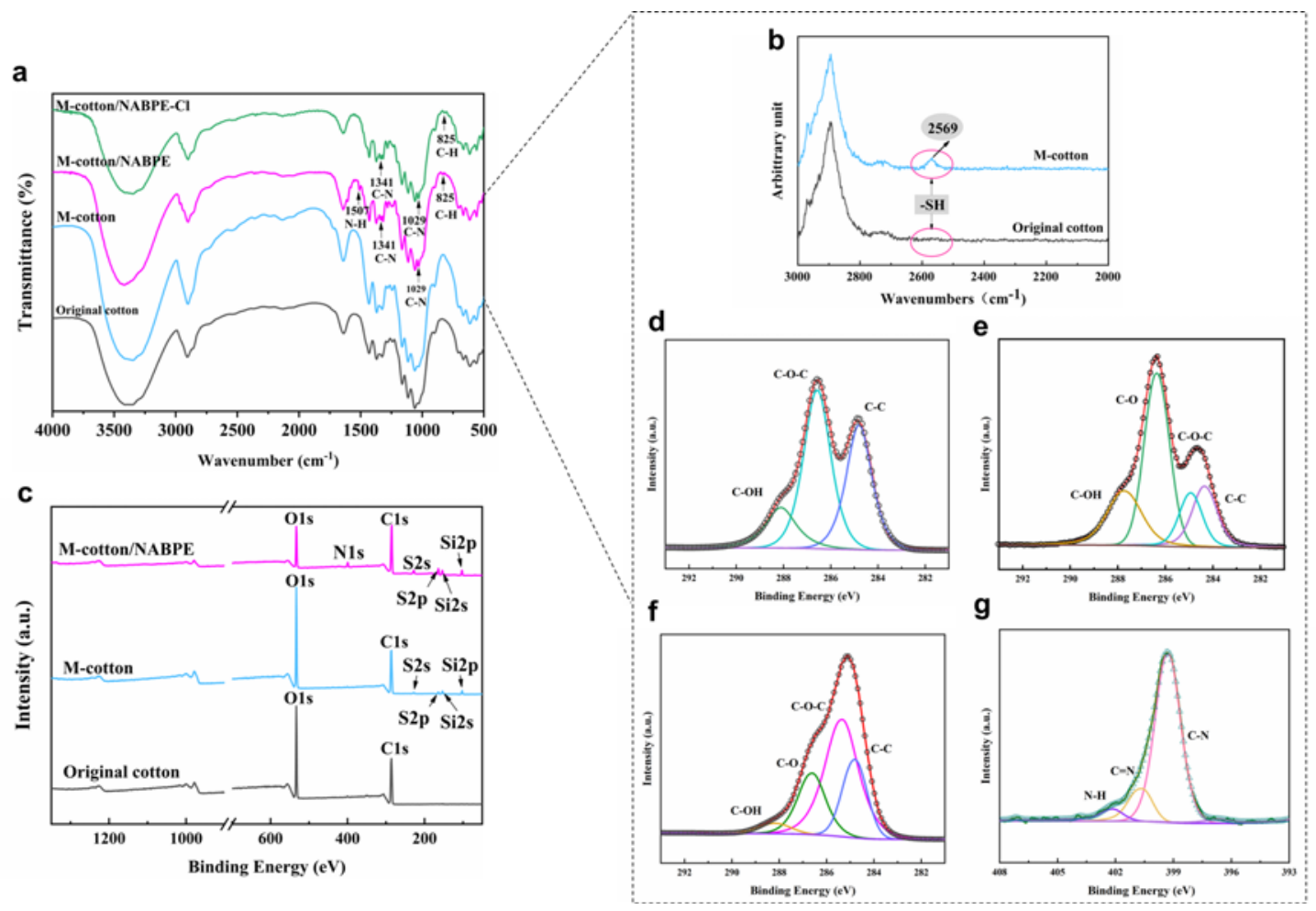

Figure 3. FT-IR (a), Raman (b), and XPS spectra (c) of the cotton sample before and after treatment; (d) C1s peak-fitting diagram of original cotton; (e) C1s peak-fitting diagram of M-cotton; C1s (f) and N1s (g) peak-fitting diagram of the M-cotton/NABPE sample. 

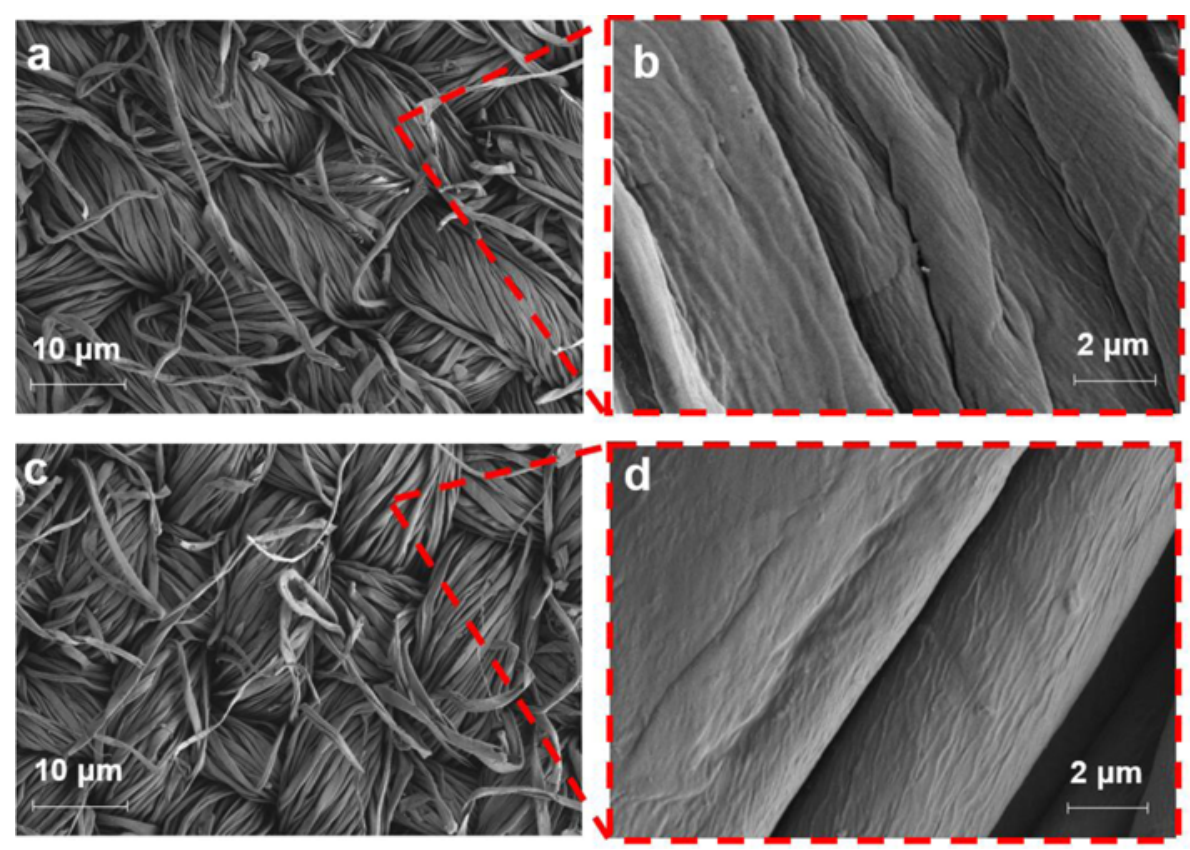

Figure 4. SEM images of ( $a, b)$ original cotton and (c, d) M-cotton/NABPE fabrics.

antibacterial rates with $99 \%$ and $98 \%$ against $E$. coli and $S$. aureus, respectively. These demonstrated that the Mcotton/NABPE has excellent antibacterial properties, and it can be further improved by chlorination treatment.

The drop-plate method was further adopted to count the viable bacteria for evaluation to the fast sterilization effect of M-cotton/NABPE-Cl. As shown in Figure 5(b), when Mcotton/NABPE-Cl and bacterial suspension were in contact for $1 \mathrm{~min}$, the antibacterial ratio against both $E$. coli and $S$. aureus reached higher than $99 \%$. Few living bacteria were found in the plates as shown in Figure 5(b) A2 and B2. When they were in contact for over $5 \mathrm{~min}$, all the bacteria were killed, as shown in Figure 5(b) A3-A5 and B3-B5. So, the antibacterial effect and rapid sterilization ability of NABPE treated fabric are better than the of AOBYID treated fabric in our previous work [29].

As shown in Figure 5(c). No inhibition zone was found around the original cotton fabric (1). On the contrary, visible aseptic halos were found around the original cotton fabric with added antibiotics (2). Moreover, no inhibition zone was found around M-cotton/NABPE (3) and M-cotton/NABPE$\mathrm{Cl}$ (4), indicating that the antibacterial agent NABPE was non-leaching.

\section{Stability and Rechargeability}

The UV irradiation can break apart chemical bonds in the $\mathrm{M}$-cotton/NABPE-Cl fabrics, thereby decreasing antibacterial activity. The storage stability and rechargeability reflected the M-cotton/NABPE-Cl fabrics' rapid antibacterial durability. Test results for UV stability, storage stability, and rechargeability are shown in Figure 6.
As shown in Figure 6(a), when exposed to UVA radiation, the active chlorine contents of M-cotton/NABPE- $\mathrm{Cl}$ fabrics declined with time. When the irradiation time was up to $12 \mathrm{~h}$, the chlorine content of the treated cotton fabrics decreased slowly, reaching at $(0.12 \pm 0.01) \%$. After $24 \mathrm{~h}$ of irradiation, a chlorine value of $(0.06 \pm 0.03) \%$ was maintained, which was much higher than previous work (the chlorine value was 0) [29], suggesting that the introduction of NAPBE could improve the UV stability of the prepared fabric. Upon rechlorination of the samples, about $74 \%$ $(0.54 \mathrm{wt} . \%)$ of the original chlorine content was regained for a good rechargeability.

The durability of M-cotton/NABPE-Cl fabrics' fast biocidal functions was evaluated through long-term storage at room temperature. Test results showed that $55 \%$ active chlorine contents $(0.41 \mathrm{wt} . \%)$ were retained after storage for 21 days, indicating a relatively stable biocidal function, as shown in Figure 6(b).

To further investigate the fabrics' rechargeability, a chlorination-quenching cycle test was conducted by 10 times $\mathrm{NaClO}$ chlorination and $\mathrm{Na}_{2} \mathrm{~S}_{2} \mathrm{O}_{3}$ reduction. Figure 6(c) displays the test results. The active chlorine contents of M-cotton/NABPE-Cl were nearly unchanged after quenching/ recharging cycles, and this result was attributed to the robust covalent bonding between NABPE and fabric. $N$-halamine structure was obtained by chlorinating the amide N-H bond on the antibacterial agent, which played a key role in rapid antibacterial property. The increase of $N$-halamine structure amount had a direct positive effect on active chlorine contents, leading to a higher and faster biocidal activity. After being repeatedly chlorinated and reduced, the active 

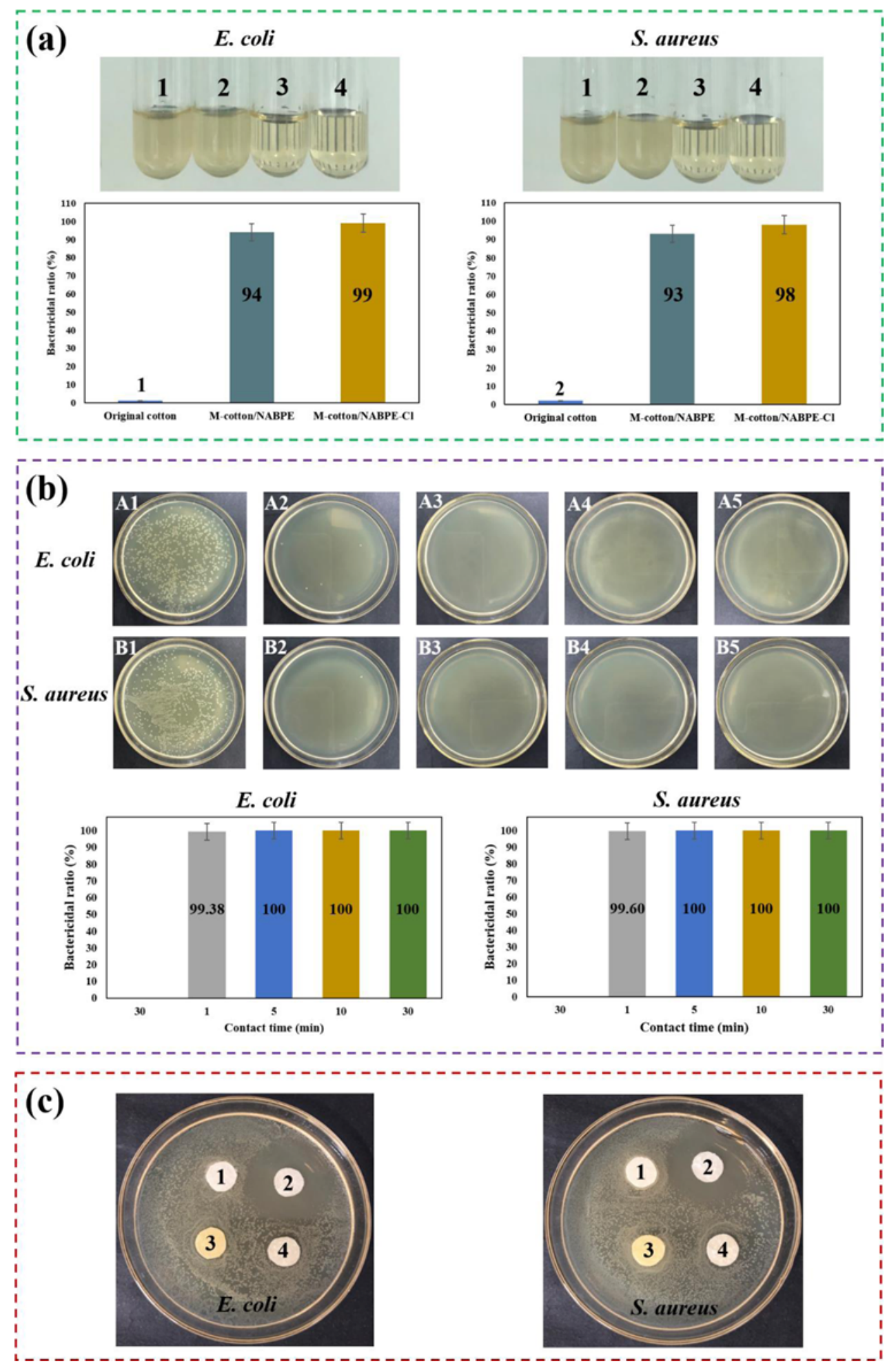

Figure 5. (a) Images and results of $E$. coli and $S$. aureus after $24 \mathrm{~h}$ incubation with the sample (1, 2, 3, and 4 are blank, control cotton fabric, $\mathrm{M}$-cotton/NABPE, and M-cotton/NABPE-Cl, respectively); (b) antibacterial properties of the samples against $E$. coli (A1-5) and $S$. aureus (B1-5): (A1 and B1) original cotton with a contact duration of $30 \mathrm{~min}$; (A2-5 and B2-5) M-cotton/NABPE-Cl with a contact duration of 1, 5, 10 , and $30 \mathrm{~min}$. The error bar indicates the standard deviation; (c) the Inhibition zone result pictures of samples against the $E$. coli and $S$. aureus: 1 and 2 are original cotton fabric and original cotton-added antibiotic fabric used as the negative and positive controls, respectively; 3 and 4 are $\mathrm{M}$-cotton/NABPE and M-cotton/NABPE-Cl, respectively. 


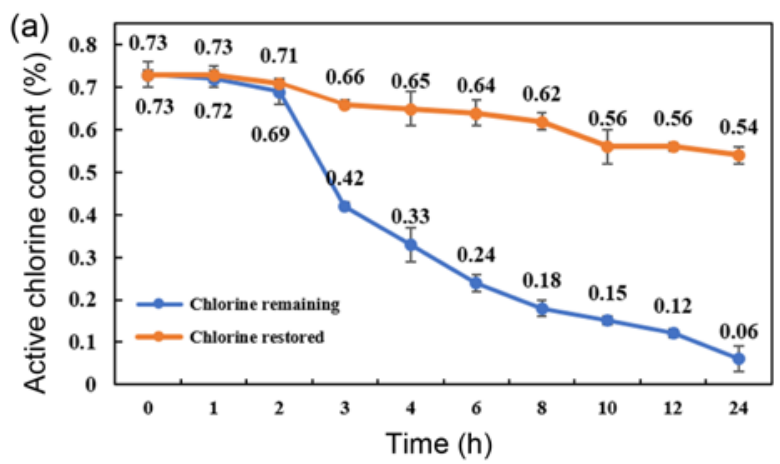

(b)
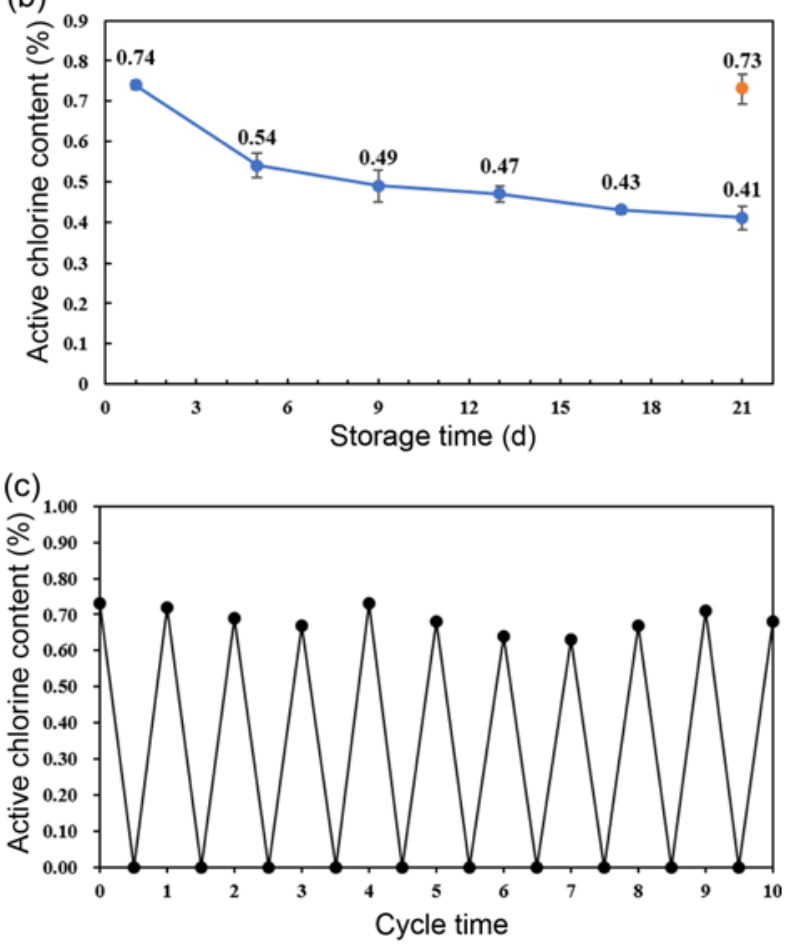

Figure 6. (a) UV light stability of $\mathrm{M}$-cotton/NABPE-Cl, (b) change of active chlorine content of M-cotton/NABPE-Cl with storage time at room temperature, and (c) active chlorine content of $\mathrm{M}$-cotton/NABPE-Cl after 10 chlorination-quenching cycle tests. The error bar indicates the standard deviation. chlorine content was still maintained at a high and stable level, thereby showing the M-cotton/NABPE fabrics' promising rechargeability.

Washing cycle test was conducted in accordance to the standard of AATCC 61-2006, and the results are displayed in Table 2. Test results showed that the concentration of active chlorine on M-cotton/NABPE-Cl fabric decreased from 0.74 wt. $\%$ to 0.27 wt. $\%$ after 25 cycles, which was attributed to the peeling of biocidal layer and the hydrolysis of $\mathrm{N}-\mathrm{Cl}$. However, the remaining active chlorine concentration was much higher than the threshold value $(0.05 \mathrm{wt} . \%)$ that can completely inactivate bacteria [34]. After 25 cycles, the active chlorine concentration could be recharged to 0.50 wt.\%. Therefore, the M-cotton/NABPE-Cl had good washing stability, and the rechargeability of the fabric was satisfactory. Moreover, after 25 washing cycles, the antibacterial fabric still maintained an antibacterial rate of $91.95 \%$ and $92.15 \%$ against $E$. coli and $S$. aureus, respectively. Compared with previous work [29], the treated fabric with NABPE maintained a better washing stability and antibacterial effect.

\section{Tensile Strength, Softness and Whiteness}

The tensile strength values of original cotton, M-cotton, M-cotton/NABPE, and M-cotton/NABPE-Cl were measured on an electronic fabric tensile tester (HD026N) according to the ASTM D5035-2006 standard. Softness was evaluated by bending length according to the ASTM D1388-96 standard, while the whiteness was measured by datacolar650 (America).

Figure 7 presents the test results of tensile strength, bending length and whiteness of original cotton, M-cotton, M-cotton/NABPE, and M-cotton/NABPE-Cl. As shown in Figure 7(a), above $95 \%$ of tensile strength was maintained in warp and weft directions for M-cotton/NABPE and Mcotton/NABPE-Cl. The slight reduction might be due to the loss of intramolecular hydrogen bonds and the substitution of hydroxyl groups on the cotton fabrics [35]. Figure 7(b) shows that the bending length increased by not more than $10 \%$, and the softness was maintained well. Besides, the

Table 2. Washing stability of M-cotton/NABPE-Cl

\begin{tabular}{|c|c|c|c|c|c|c|}
\hline \multirow[b]{2}{*}{ washing cycles } & \multirow{2}{*}{$\begin{array}{c}\text { Remained } \\
\text { chlorine }\left(\mathrm{Cl}^{+} \%\right)\end{array}$} & E. coll $^{\mathrm{a}}$ & S. aureus & \multirow{2}{*}{$\begin{array}{l}\text { Recovered chlorine after } \\
\text { rechlorination } \\
\left(\mathrm{Cl}^{+} \%\right)\end{array}$} & E. coli $^{\mathrm{a}}$ & S. aureus ${ }^{\mathrm{b}}$ \\
\hline & & $\begin{array}{c}\text { Bacterial } \\
\text { reduction }(\%)\end{array}$ & $\begin{array}{c}\text { Bacterial } \\
\text { reduction }(\%)\end{array}$ & & $\begin{array}{c}\text { Bacterial } \\
\text { reduction }(\%)\end{array}$ & $\begin{array}{c}\text { Bacterial } \\
\text { reduction }(\%)\end{array}$ \\
\hline 0 & $0.74 \pm 0.02$ & 100 & 100 & $0.74 \pm 0.03$ & 100 & 100 \\
\hline 5 & $0.54 \pm 0.01$ & 100 & 100 & $0.57 \pm 0.02$ & 100 & 100 \\
\hline 10 & $0.52 \pm 0.03$ & 100 & 100 & $0.54 \pm 0.01$ & 100 & 100 \\
\hline 20 & $0.39 \pm 0.02$ & 99.83 & 99.78 & $0.52 \pm 0.02$ & 100 & 100 \\
\hline 25 & $0.27 \pm 0.02$ & 91.95 & 92.15 & $0.49 \pm 0.02$ & 100 & 100 \\
\hline
\end{tabular}

${ }^{a}$ Inoculum concentration was $5.96 \times 10^{8} \mathrm{CFU} /$ sample and ${ }^{\mathrm{b}}$ inoculum concentration was $4.46 \times 10^{8} \mathrm{CFU} / \mathrm{sample}$. 
(a)

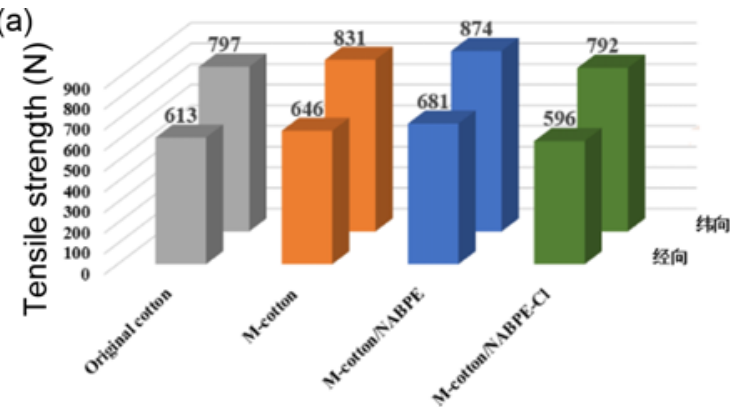

(b)

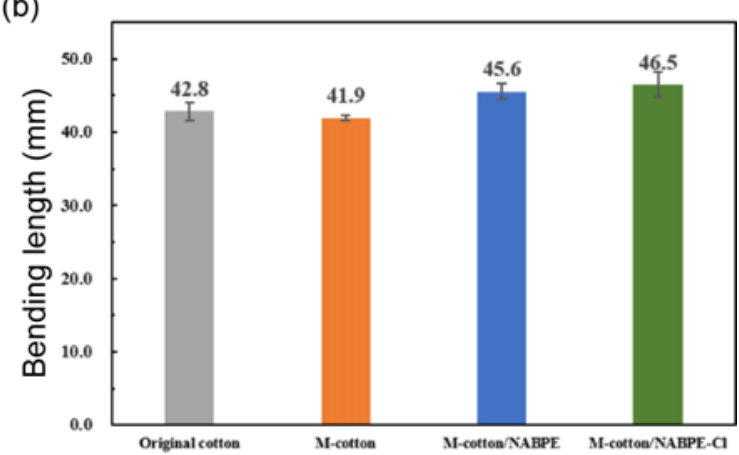

(c)

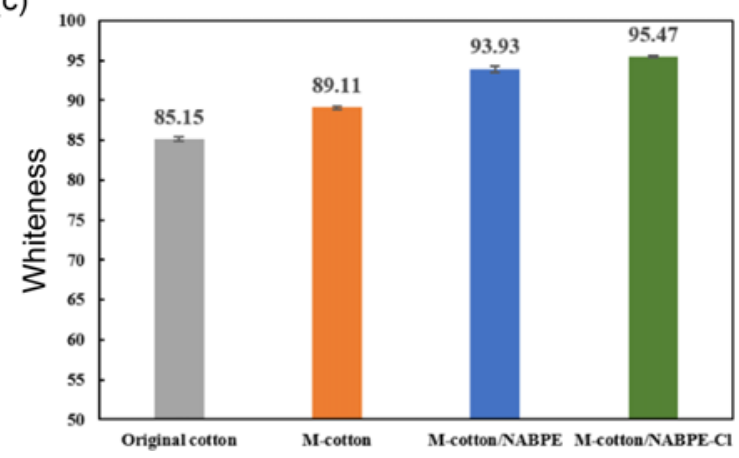

Figure 7. Tensile strength (a), bending length (b) and whiteness (c) of the fabric before and after treatment.

effect of treatment with NABPE on the whiteness of the fabric was minimal (Figure 7(c)).

\section{Conclusion}

A water-soluble piperazinyl Schiff base NABPE was successfully synthesized. The NABPE showed good antibacterial activity both against $E$. coli and $S$. aureus compared to AOBYID. M-cotton/NABPE fabrics were obtained by MPTES pre-treatment and thiol-ene click reaction, and M-cotton/NABPE-Cl fabrics were obtained by chlorinating the M-cotton/NABPE. These fabrics all exhibited enhanced high and fast biocidal property, which suitable for preparing disposable antibacterial materials. Moreover, the NABPE coating had little effect on the tensile strength, softness and whiteness. Good UV stability, longterm stability, robust rechargeability, and washing durability indicated that the fabric had promising application.

\section{Acknowledgments}

This work was supported by the Chongqing Postgraduate Innovation Research and Innovation Project (grant number CYS20118), the Hunan Province Key R \& D Projects (grant number 2016GK2020) and the Opening Project of Hunan Engineering Laboratory for Preparation Technology of Polyvinyl Alcohol Fiber (grant number HGY201607).

\section{References}

1. L. Li, P. Duan, Q. Xu, X. J. Zhang, and X. Liu, Fiber. Polym., 21, 1965 (2020).

2. S. Chen, L. Yuan, Q. Li, J. Li, X. Zhu, Y. Jiang, O. Sha, X. Yang, J. H. Xin, J. Wang, F. J. Stadler, and P. Huang, Small, 12, 3516 (2016).

3. Y. Chen, Y. Ma, Q. He, Q. Han, Q. Zhang, and Q. Chen, Cellulose, 26, 5033 (2019).

4. M. Küçük and M. L. Öveçoğlu, Cellulose, 27, 1773 (2019).

5. P. Duan, Q. Xu, S. Shen, Y. Zhang, L. Zhang, F. Fu, and X. Liu, Fiber. Polym., 20, 1803 (2019).

6. N. Nazi, V. Humblot, and C. Debiemme-Chouvy, Langmuir, 36, 11005 (2020).

7. Y. Zhao, B. Wei, M. Wu, H. Zhang, J. Yao, X. Chen, and Z. Shao, Int. J. Biol. Macromol., 155, 1468 (2020).

8. W. Chen, Y. Zhu, Z. Zhang, Y. Gao, W. Liu, Q. Borjihan, H. Qu, Y. Zhang, Y. Zhang, Y.-J. Wang, L. Zhang, and A. Dong, Chemical Eng. J., 379, 122238 (2020).

9. S. Zhang, L. Li, X. Ren, and T.-S. Huang, Int. J. Biol. Macromol., 161, 1070 (2020).

10. M. Yin, Y. Wang, Y. Zhang, X. Ren, Y. Qiu, and T.-S. Huang, Carbohyd. Polym., 232, 115823 (2020).

11. S. Kinani, B. Richard, Y. Souissi, and S. Bouchonnet, TrAC-Trend Anal. Chem., 33, 55 (2012).

12. W. Ma, L. Li, X. Ren, and T.-S. Huang, Surf. Coat. Tech., 379, 125021 (2019).

13. F. Hui and C. Debiemme-Chouvy, Biomacromolecules, 14, 585 (2013).

14. X. Ren, L. Kou, J. Liang, S. D. Worley, Y.-M. Tzou, and T. S. Huang, Cellulose, 15, 593 (2008).

15. J. Liang, Y. Chen, K. Barnes, R. Wu, S. D. Worley, and T. S. Huang, Biomaterials, 27, 2495 (2006).

16. K. Barnes, J. Liang, R. Wu, S. D. Worley, J. Lee, R. M. Broughton, and T. S. Huang, Biomaterials, 27, 4825 (2006).

17. Y. Liu, Q. He, R. Li, D. Huang, X. Ren, and T.-S. Huang, Fiber. Polym., 17, 2035 (2016).

18. Y. Chen, X.-S. Zhong, and Q. Zhang, Ind. Eng. Chem. Res., 51, 9260 (2012).

19. I. Cerkez, H. B. Kocer, S. D. Worley, R. M. Broughton, 
and T. S. Huang, React. Funct. Polym., 72, 673 (2012).

20. Y. Chen, Q. He, G. Ren, C. Feng, N. Li, H. Yu, and Q. Han, J. Appl. Polym. Sci., 135, 46624 (2018).

21. Y. Chen, Q. Zhang, Q. Han, Y. Mi, S. Sun, C. Feng, H. Xiao, P. Yu, and C. Yang, J. Appl. Polym. Sci., doi: 10.1002/app.44721 (2017).

22. H. B. Kocer, I. Cerkez, S. D. Worley, R. M. Broughton, and T. S. Huang, ACS Appl. Mater. Inter, 3, 2845 (2011).

23. K. Ma, Y. Liu, Z. Xie, R. Li, Z. Jiang, X. Ren, and T.-S. Huang, Ind. Eng. Chem. Res., 52, 7413 (2013).

24. J. Liang, Y. Chen, X. Ren, R. Wu, K. Barnes, S. D. Worley, R. M. Broughton, U. Cho, H. Kocer, and T. S. Huang, Ind. Eng. Chem. Res., 46, 6425 (2007).

25. S. Li, X. Lin, Y. Liu, R. Li, X. Ren, and T.-S. Huang, Cellulose, 26, 4213 (2019).

26. J. Liu, C. Dong, Z. Zhang, D. Wei, and Z. Lu, Fiber. Polym., 21, 273 (2020).

27. Y. Chen, Y. Wang, C. Feng, Q. He, Q. Chen, Z. Wang, and
Q. Han, Int. J. Biol. Macromol., 154, 173 (2020).

28. Z. Ma, M. Yin, M. Zhang, Z. Qi, X. Ren, and T.-S. Huang, Fiber. Polym., 20, 244 (2019).

29. W. Wen, Z. Zhang, L. Jing, and T. Zhang, Cellulose, 27, $7243(2020)$.

30. H. Xu, Z. Fang, W. Tian, Y. Wang, Q. Ye, L. Zhang, and J. Cai, Adv. Mater., 30, e1801100 (2018).

31. D. Xu, S. Wang, J. Hu, Y. Liu, Z. Jiang, and P. Zhu, Cellulose, 28, 3265 (2021).

32. X. Zhang, M. Zhu, W. Wang, and D. Yu, Prog. Org. Coat., 120, 10 (2018).

33. R. Bai, Q. Zhang, L. Li, P. Li, Y.-J. Wang, O. Simalou, Y. Zhang, G. Gao, and A. Dong, ACS Appl. Mater. Inter., 8, 31530 (2016).

34. Y. Liu, Y. Liu, X. Ren, and T. S. Huang, Appl. Surf. Sci., 296, 231 (2014).

35. T. Mu, N. Pan, Y. Wang, X. Ren, and T.-S. Huang, Fiber. Polym., 19, 2284 (2018). 